\title{
Development of an Inhalation System of High Melting Point Metal Fumes and Its Use for Exposure of Rats to Chromium and Nickel Fumes
}

\author{
Fumio SERITA, Katsunori HOMMA, Kazuo FUKUDA, \\ Katsuhiko SAWATARI, Yasutomo SUZUKI and Tadao TOYA \\ National Institute of Industrial Health \\ 21-1, Nagao 6-chome, Tama-ku, Kawasaki 214, Japan
}

(Received August 2, 1990 and in revised form October 12, 1990)

\begin{abstract}
An experimental inhalation system was developed for fumes generated from powders of high melting point metals such as chromium, nickel, manganese and iron. The system consisted of a plasma flame metal sprayer as a fume generator, a granular bed type fume collector, a fluidized bed aerosol generator, an exposure and a control chamber of a horizontal-flow type and inhalant monitoring and controlling units. Performance of the chambers was ensured by a distribution test using flyash as a test aerosol.

Using this system, rats were exposed to chromium fumes for one week or to nickel fumes for two months. The exposure concentrations of the chromium and nickel fumes were 1.85 $\pm 0.55 \mathrm{mg} / \mathrm{m}^{3}$ and $0.51 \pm 0.15 \mathrm{mg} / \mathrm{m}^{3}$ (mean $\pm S D$ ), near the target levels of $2 \mathrm{mg} / \mathrm{m}^{3}$ and 0.5 $\mathrm{mg} / \mathrm{m}^{3}$, respectively. The mass median aerodynamic diameter and the geometric standard deviation of the chromium fumes were $2.1 \mu \mathrm{m}$ and 2.00 , respectively. Those of the nickel fumes were $3.7 \mu \mathrm{m}$ and 1.74, respectively. Species analysis of these fume particles revealed that $26.4 \%$ of the total chromium was hexavalent and the residue was trivalent and that 1 $-3 \%$ of the total nickel was nickel(III) and the residue was nickel(II). Inhaled-metal concentrations in the lungs showed steady increases with the exposure periods and were within the normal range of variation.

On the basis of these results, it is concluded that this system is useful for long-term inhalation experiments using high melting point metal fumes.

Key words: High melting point metals-Fumes-Generation-Chromium-Nickel-Inhalation-Rat
\end{abstract}

\section{INTRODUCTION}

Most of the fume particles of high melting point metals such as chromium, nickel and manganese existing in the atmospheres of both general and working environments are considered to be oxides generated primarily from metal-melting processes in industries. ${ }^{1}$ To investigate the biological effects of the airborne metal fumes, animal experiments of inhalation exposure are necessary. However few 
inhalation experiments using fumes of high melting point metals have been carried out. The main reason is that controlled generation of these metal fumes suitable for inhalation exposure, e.g. desirable and constant fume concentrations, respirable particle sizes, etc., is difficult, because of the high melting points of the metals.

In this study, the previously reported fume-generating system of high melting point metals ${ }^{2)}$ was further improved for inhalation experiments. The inhalation system was equipped also with newly developed exposure and control chambers of a horizontal-flow type. Using this system, rats were repeatedly exposed to chromium fumes for one week or nickel fumes for two months. The main purpose of this paper is to describe structural details and performance of the inhalation system. To demonstrate the applicability of this system to inhalation experiments, some brief results from inhalation exposure are described.

\section{Methods}

\section{Instruments for fume generation and inhalation}

\section{Outline of system}

The system for fume generation and inhalation was composed of some primary components. They were a plasma flame metal sprayer (PFMS), an aerosol chamber, a granular bed type fume collector (GBFC), a fluidized bed aerosol generator(FBAG), an exposure and a control chamber and inhalant monitoring and controlling units.

\section{PFMS, aerosol chamber and GBFC}

Figure 1 shows a schematic diagram of PFMS, an aerosol chamber and GBFC. Metal fumes were generated from metal powders with PFMS (Type $7 \mathrm{M}$, METCO, New York, U.S.A.) and blown into the aerosol chamber $(105 \mathrm{~cm} \times 105$ $\mathrm{cm} \times 106 \mathrm{~cm})$. The details of the structure and general handling of PFMS were described previously. ${ }^{2} \quad$ The operating conditions of this instrument for the generation of chromium and nickel fumes are listed in Table 1.

Fume particles dispersing in the aerosol chamber were collected with GBFC, which was a box made of stainlees-steel plates (Fig. 1). It was $30 \mathrm{~cm}$ high, 40 $\mathrm{cm}$ wide and $30 \mathrm{~cm}$ deep. The box was divided into upper and lower compartments by a stainless-steel screen. A granular bed about $3 \mathrm{~cm}$ thick was prepared by covering the screen with glass beads about $0.4 \mathrm{~mm}$ in diameter. A pipe was fixed at a side of the upper compartment and the opposite side of the lower one. The upper (inlet) pipe was connected to the outlet of the aerosol chamber. The lower (outlet) pipe was connected to a suction pump through a filter.

The metal fumes in the aerosol chamber were sucked into GBFC with an air stream $\left(3 \mathrm{~m}^{3} / \mathrm{min}\right)$ blown through the granular bed. The fume particles were collected with the granular bed. The collected particles, together with the glass 


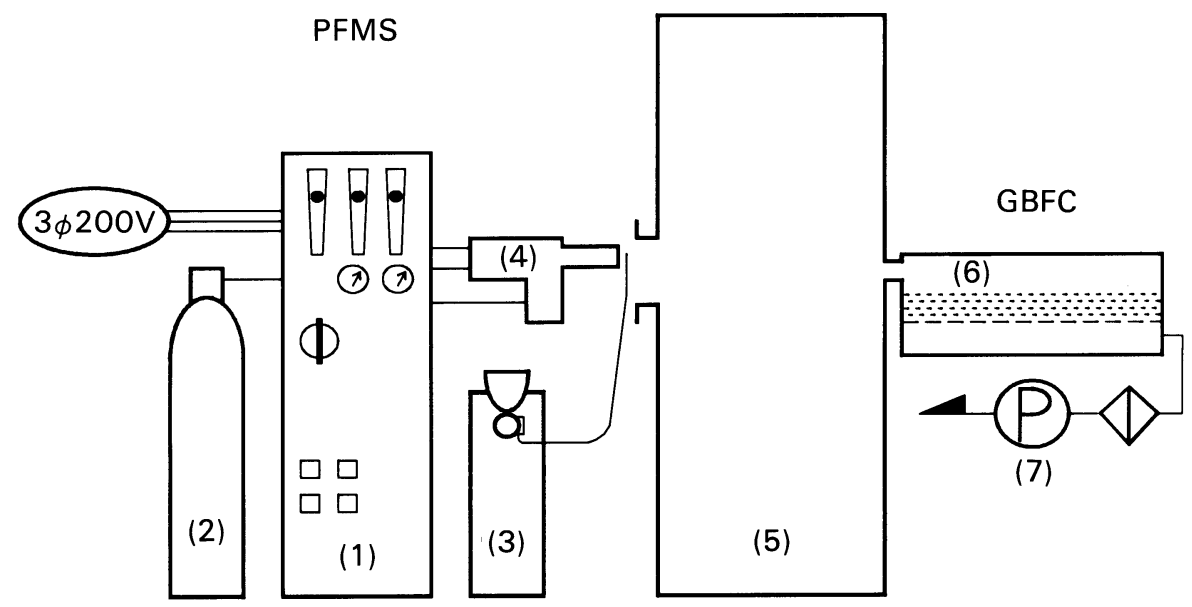

Fig. 1. Schematic diagram of plasma flame metal sprayer (PFMS), aerosol chamber and glanular bed type fume collector (GBFC).
1. Control console
2. Gas cylinder
3. Powder feeder
4. Plasma gun
5. Aerosol chamber
6. Granular bed
7. Pump

Table 1. Operating conditions of PFMS* for generation of chromium and nickel fumes

\begin{tabular}{|c|c|c|c|c|c|}
\hline \multirow[b]{2}{*}{ Fumes } & \multicolumn{2}{|c|}{ Electric condition } & \multicolumn{2}{|r|}{ Gas flow } & \multirow{2}{*}{$\begin{array}{l}\text { Powder } \\
\text { feed rate } \\
(\mathrm{g} / \mathrm{min})\end{array}$} \\
\hline & $\begin{array}{l}\text { Voltage } \\
\text { (V) }\end{array}$ & $\begin{array}{l}\text { Current } \\
\text { (A) }\end{array}$ & Argon & $(1 / \mathrm{min}){ }^{\text {Helium }}$ & \\
\hline Chromium & 35 & 1000 & 54 & 0 & 2.5 \\
\hline Nickel & 50 & 940 & 32 & 75 & 18.7 \\
\hline
\end{tabular}

* Plasma flame metal sprayer.

beads, were transferred into a glass vessel. By hard shaking of the vessel by hand for several minutes, the surfaces of the glass beads were uniformly coated with the fume particles. The particle-coated glass beads were used to redisperse the particles with FBAG as described below.

\section{FBAG system}

A schematic diagram of FBAG (Fluidized Bed Dust Generator Model 3217, Nihon Kagaku Kogyo, Osaka, Japan) is shown in Fig. 2. It was fundamentally the same as that reported by Tanaka and Akiyama. ${ }^{3)}$ The particle-coated glass beads were poured into the hopper, then fed into the cylinder of the fluidized bed by rotating the screw feeder. To adjust the supply of the glass beads into the cylinder, the rotation of the screw feeder was controllable from 20 to $40 \mathrm{rpm}$. The cylinder was made of an aluminium pipe $7 \mathrm{~cm}$ i.d. and $60 \mathrm{~cm}$ high. An overflow tank was connected to the side of the cylinder. A stainless-steel screen was placed $5 \mathrm{~cm}$ above the bottom of the cylinder. The glass beads fed into the cylinder were fluidized by a constant air stream $(601 / \mathrm{min})$ blown up through the 


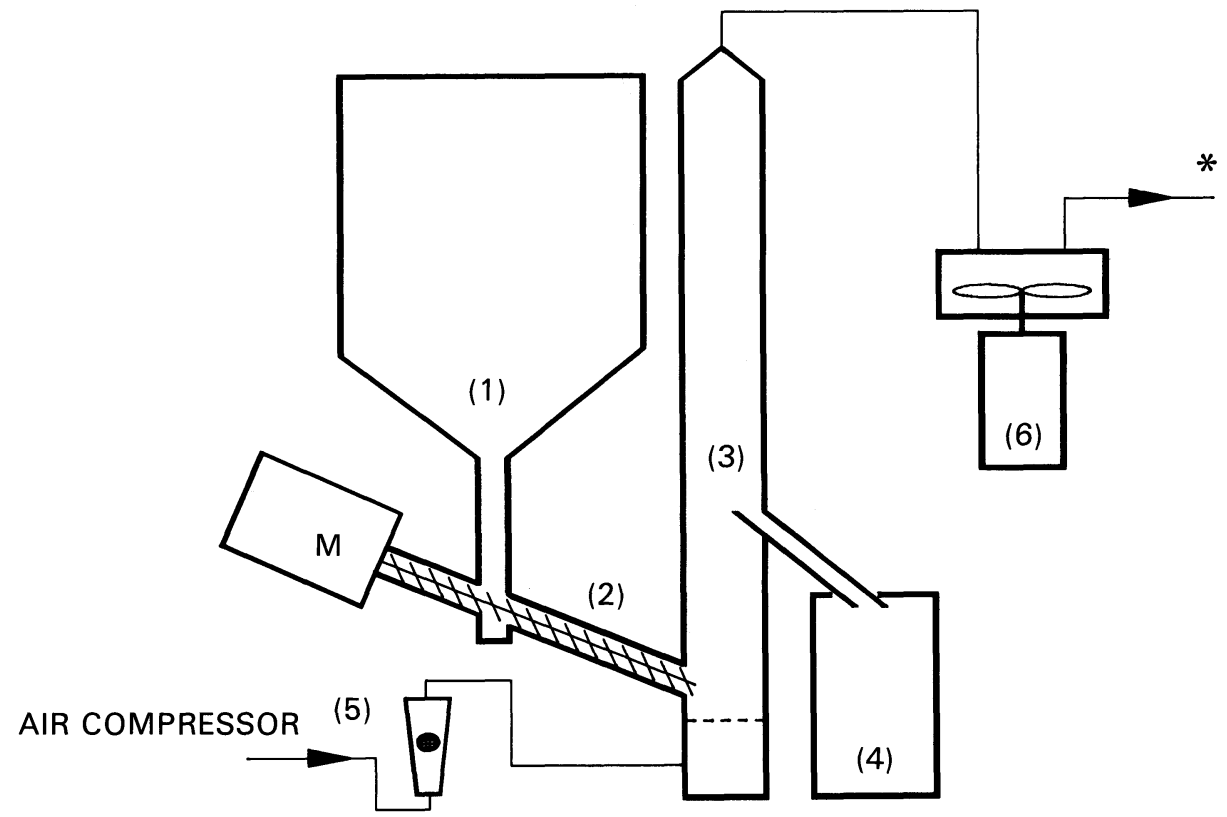

Fig. 2. Schematic diagram of fluidized bed aerosol generator (FBAG).
1 Hopper
2. Screw feeder
3. Fluidized bed
4. Overflow tank
5. Flow meter
6. Crusher

M. Motor

* Connected to the inlet of the mixing chamber shown in Fig. 3.

screen. The fume particles were released from the surfaces of the fluidized glass beads and redispersed into aerosol. The aerosol particles were supplied to the exposure chamber after deaggregation into smaller size with a crusher. The blades of the crusher rotated at $10,000 \mathrm{rpm}$.

In a preliminary experiment to determine the effect of the crusher, the physical characteristics of chromium fumes prepared with and without the crusher were measured. When the system operated, the concentration, mass median aerodynamic diameter (MMAD) and geometric standard deviation $(\sigma \mathrm{g})$ of the fumes in the exposure chamber were $8.29 \mathrm{mg} / \mathrm{m}^{3}, 3.0 \mu \mathrm{m}$ and 2.1 , respectively. However, the concentration decreased to $2.97 \mathrm{mg} / \mathrm{m}^{3}$ after it stopped. The other parameters remained scarecely changed $(\mathrm{MMAD}=3.2 \mu \mathrm{m}, \sigma \mathrm{g}=2.0)$. The results clearly show the deaggregation effect of the crusher. Probably some of the fume particles generated with FBAG were aggregated. The resultant large particles were not supplied in the chamber due to the deposition in the connecting pipes.

Exposure and control chambers

Structure and Sizes

As shown in Fig. 3, the exposure chamber was a rectangular cross-section type and was constructed of stainless steel. Its inner dimensions were $175 \mathrm{~cm} \mathrm{high,} 100$ 
(1)

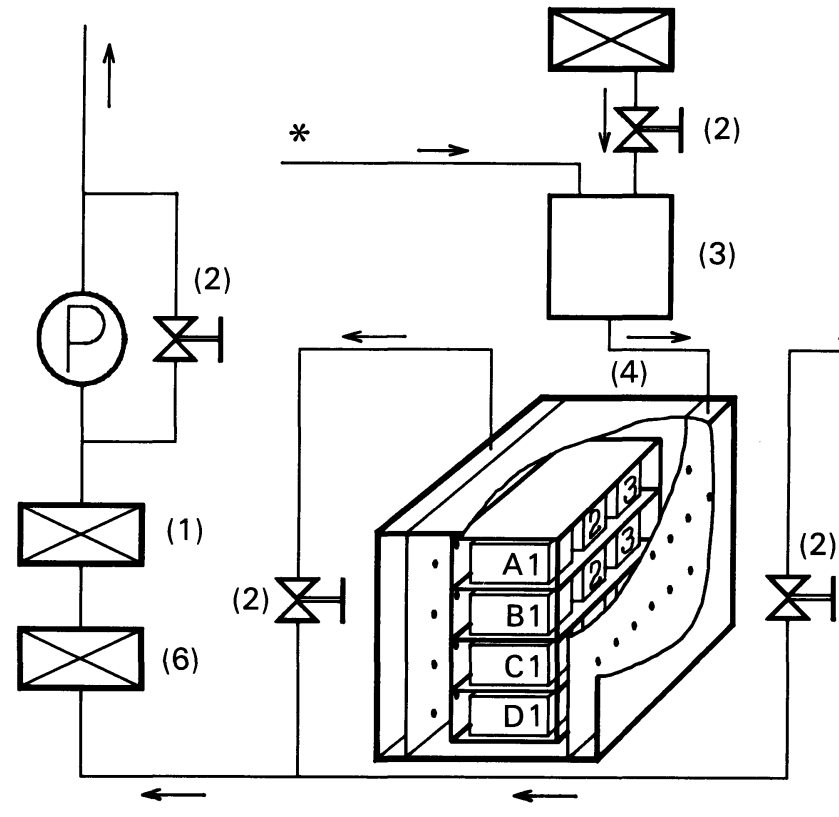

(1)

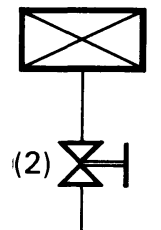

Fig. 3. Schematic diagram of exposure and control chambers.
1. HEPA filter
2. Flow control valve
4. Exposure chamber
5. Control chamber
3. Mixing chamber
6. Prefilter
* Connected to the outlet of FBAG shown in Fig. 2.

$\mathrm{cm}$ wide and $120 \mathrm{~cm}$ deep. The inner volume was $2.1 \mathrm{~m}^{3}$. It was equipped with two fixed glass windows on both sides and a glass door on its front. A pair of plastic rectification plates with 36 orifices $10 \mathrm{~mm}$ in diameter were set at $15 \mathrm{~cm}$ inside the chamber windows. Each rectification plate was equipped with four horizontal lines of nine orifices. The level of each line was directed at the central position of the cage height. Air was introduced through the orifices of the inlet rectification plate and removed through the opposite ones. Expected effects of the plates were the reduction of short pathways of air in the chamber and the formation of a uniform air flow. The structure and sizes of the control chamber were the same as those of the exposure chamber.

A mobile cage rack with four shelves, each of which kept three cages (five rats a cage), was placed in each chamber. The rack was provided with automatic watering and feeding apparatuses. Urinary and fecal catch pans were situated under the cages.

\section{Chamber performance test}

Flyash was used to examine three-dimensional distribution of aerosol concentrations in the exposure chamber. Flyash aerosol $(\mathrm{MMAD}=2.5 \mu \mathrm{m}, \sigma \mathrm{g}=1.6)$ was generated with a dust feeder (Type MF-2, Sibata Scientific Technology, Tokyo, 
Japan) connected to the mixing chamber instead of the FBAG system. The aerosol was supplied to the exposure chamber equipped with 12 empty cages. The cages were numbered from $\mathrm{A}^{-1}$ to $\mathrm{D}^{-3}$ as shown in Fig. 3 and Table 2. The aerosol concentrations were determined at the centers of the cages one after another by a light scattering type dust meter (Digital Dust Indicator P-5, Sibata). The determination was performed at 20,30 and 40 chamber-air changes per hour. Each measurement was standardized to correct for time-dependent fluctuation of the aerosol concentrations. The standardization was carried out by a "representative" aerosol concentration determined simultaneously with a light scattering type dust meter (Digital Dust Indicator Ap-638, Sibata) set in chamber $\mathrm{A}-3$.

\section{Physical and chemical characterization of metal fumes}

Chromium and nickel fumes were generated from the metal powders smaller than 200 mesh purified up to $99.9 \%$ (Soekawa Chemicals, Tokyo, Japan). No nitrogen oxide was detected from chromium fume particles colorimetrically by the naphthylethylenediamine method with zinc as a reductant. ${ }^{4)}$ The metal fumes were supplied to the exposure chamber by the procedures described above. Digital Dust Indicator AP-638 was used for continuous monitoring of relative concentrations (count per minute) of the fumes in the chamber. The measurements were automatically recorded at one-minute intervals, from the beginning to the end of the daily exposure. Daily means of the relative concentrations were calculated. Mass concentration of the fumes was also measured once a day. The sample used for this measurement was collected on a Teflon-treated glass fiber filter (T60A20, Pallflex Products, Conn., U.S.A.) at a flow rate of $201 / \mathrm{min}$ for $30 \mathrm{~min}$. Using a conversion coefficient between the mass concentration and the time-weighted average of the relative concentrations recorded within the same period, the daily mean of the relative concentrations was converted to mass concentration. Exposure concentration of the fumes was defined by an average of the converted mass concentrations obtained in the whole exposure period.

Size distribution of the fume particles was examined with an Andersen type cascade impactor (Model AN-200Z, Tokyo Dylec, Tokyo, Japan) using glass fiber filters (T60A20) as impaction plates. Fume Particles for scanning electron microscopic observation were collected from the exposure chamber on a $0.6 \mu \mathrm{m}$ Nuclepore filter.

Chromium fume samples collected on Teflon membrane filters (FP 100, Sumitomo Electric, Tokyo, Japan) from the exposure chamber were analyzed for chromium(III) and chromium(VI) species, according to the method reported by Sawatari and Serita. ${ }^{5}$ ) Nickel fume samples collected from the aerosol chamber were analyzed for nickel(II) and nickel(III) oxides, according to the method reported by Sawatari. ${ }^{6}$ 
Table 2. Distribution of flyash aerosol concentrations in exposure chamber at different chamber-air changes

\begin{tabular}{|c|c|c|c|}
\hline \multirow{3}{*}{ Cage number* } & \multicolumn{3}{|c|}{ Aerosol concentration (CPM) } \\
\hline & \multicolumn{3}{|c|}{ Chamber-air change per hour } \\
\hline & 20 & 30 & 40 \\
\hline A-1 & 342 & 380 & NT \\
\hline$A-2$ & 338 & 375 & 370 \\
\hline$A-3$ & 343 & 378 & NT \\
\hline B-1 & 353 & 367 & NT \\
\hline B-2 & 339 & 363 & 372 \\
\hline B-3 & 361 & 368 & NT \\
\hline $\mathrm{C}-1$ & 349 & 362 & NT \\
\hline $\mathrm{C}-2$ & 345 & 361 & 368 \\
\hline $\mathrm{C}-3$ & 344 & 366 & NT \\
\hline $\mathbf{D}^{-1}$ & 339 & 357 & NT \\
\hline D-2 & 337 & 357 & 360 \\
\hline D-3 & 339 & 359 & NT \\
\hline Mean & 344 & 366 & 368 \\
\hline SD & 6.83 & 7.56 & 4. 55 \\
\hline CV (\%) & 1. 99 & 2. 07 & 1. 24 \\
\hline
\end{tabular}

NT: Not tested.

${ }^{*} \mathrm{~A}, \mathrm{~B}, \mathrm{C}$ and D denote the shelf levels from top to bottom. 1,2 and 3 denote the locations of the front, middle and rear cages in each shelf, respectively.

\section{Animal experiments}

\section{Exposure conditions}

Eight-week-old Sprague-Dawley male rats (Clea Japan, Tokyo, Japan) fed on a sterilized commercial pelleted diet (CE-2, Clea Japan) were housed in 12 cages in each chamber. Sixty animals were used in both the experimental and control groups. The animals in the experimental group were exposed to chromium fumes at the target level of $2 \mathrm{mg} / \mathrm{m}^{3}$ for one week (five hours a day, five days a week) at a temperature of about $26^{\circ} \mathrm{C}$. The fume concentration in the exposure chamber was controlled by manual adjustment of the rotation of the screw feeder in the FBAG system (Fig 2). The chamber-air change was 13 times an hour. The control animals were kept in the control chamber for the same experimental period. The animals in both groups were always given sterilized tap water ad libitum, but no diet during inhalation. Animals of the same strain and same number as those described above were used for inhalation studies of nickel fumes at the target level of $0.5 \mathrm{mg} / \mathrm{m}^{3}$ for two months. The other experimental conditions were the same as those in the experiment with chromium fume exposure.

\section{Analysis of chromium and nickel of the lung}

The chromium levels of the lungs $(\mathrm{N}=5)$ exposed to chromium fumes were 
determined at the first, third and fifth days of the experiment. The control levels of lung chromium $(\mathrm{N}=5)$ were determined at the first and fifth days. The nickel levels of the lungs $(\mathrm{N}=3$ or 4$)$ were determined after inhalation of nickel fumes for two, four and six weeks and two months. The control levels of lung nickel $(\mathrm{N}=3$ or 4$)$ were determined on the same schedule. These animals were sampled at random from the respective groups.

The lungs were removed under Nembutal anesthesia and the tissues were digested on a hot plate in concentrated nitric acid and hydrogen peroxide. The digestants were dissolved in dilute nitric acid and used for chromium or nickel determination. The chromium determination on the lung samples of the chromium-exposed and control groups, and the nickel determination on the nickelexposed animals were carried out using a flame atomic absorption spectrometer (Zeeman 6000, Hitachi, Tokyo, Japan). The nickel levels in the control samples were determined using an electrothermal atomic absorption spectrometer (Zeeman 5000, Perkin Elmer, Norwalk, CT, U.S.A).

Other test animals were used to examine the pathological effects of inhalation on the lungs, and bone marrow cells and lymphocytes were studied cytogenetically. Short communications on the results of the pathological examination and cytogenetic analysis have been reported. ${ }^{7-10)}$

\section{Results}

\section{Chamber performance test}

The performance test of the exposure chamber revealed that the coeffiecients of variation of the flyash aerosol concentrations in the chamber ranged from 1.2 to 2.1\% (Table 2). There was no significant effect of the different chamber-air changes on the distiribution of flyash aerosols.

\section{Characteristics of metal fumes}

The particles of chromium and nickel fumes in the exposure chamber were nearly spherical as shown in Fig. 4A and B. As listed in Table 3, the exposure

Table 3. Exposure concentrations and particle sizes of chromium and nickel fumes

\begin{tabular}{lcc}
\hline & Chromium fumes $^{(1)}$ & Nickel fumes $^{(2)}$ \\
\hline $\begin{array}{l}\text { Exposure concentration } \\
\left(\mathrm{mg} / \mathrm{m}^{3}, \text { mean } \pm \mathrm{SD}\right)\end{array}$ & $1.85 \pm 0.55$ & $0.51 \pm 0.15$ \\
$\mathrm{MMAD}^{(4)}(\mu \mathrm{m})$ & 2.1 & 3.7 \\
$\sigma \mathrm{g}^{(5)}$ & 2.00 & 1.74 \\
\hline (1) For one-week exposure. & & \\
(2) For two-month exposure. & \\
(3) Refer to the text. & \\
(4) Mass median aerodynamic diameter. & \\
(5) Geometric standard deviation. &
\end{tabular}


A

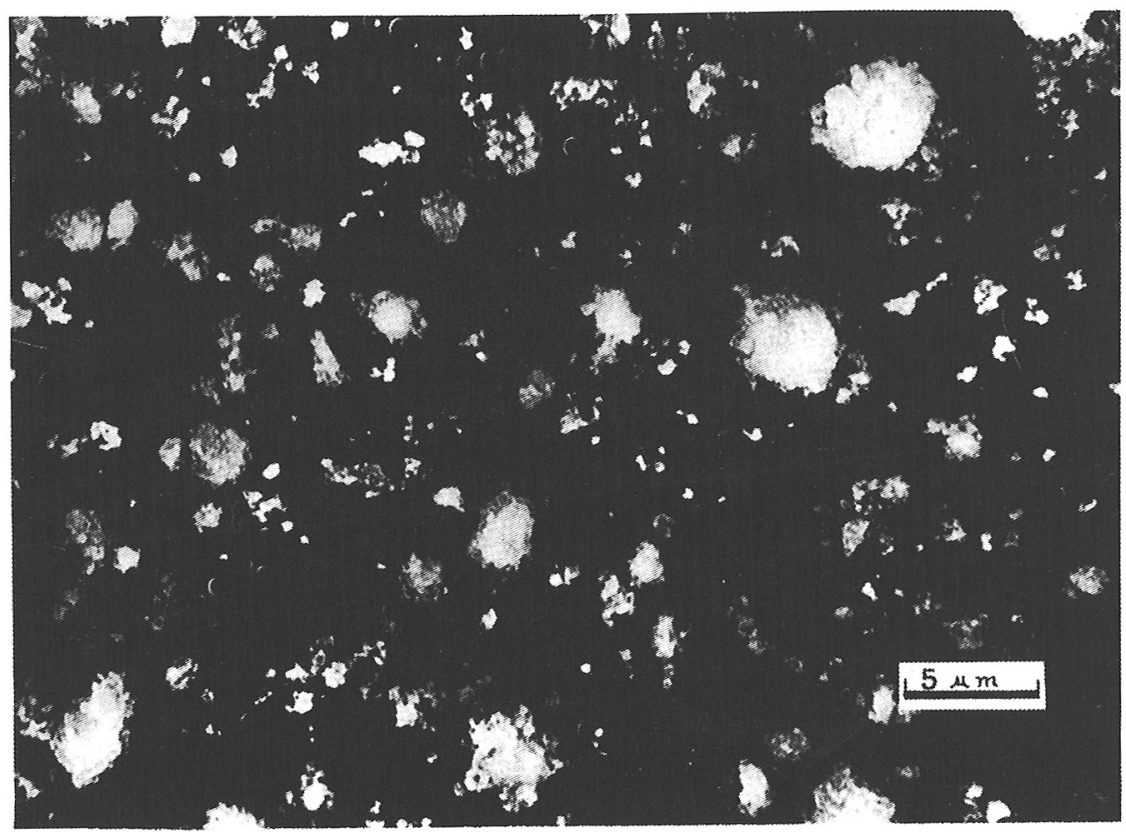

B

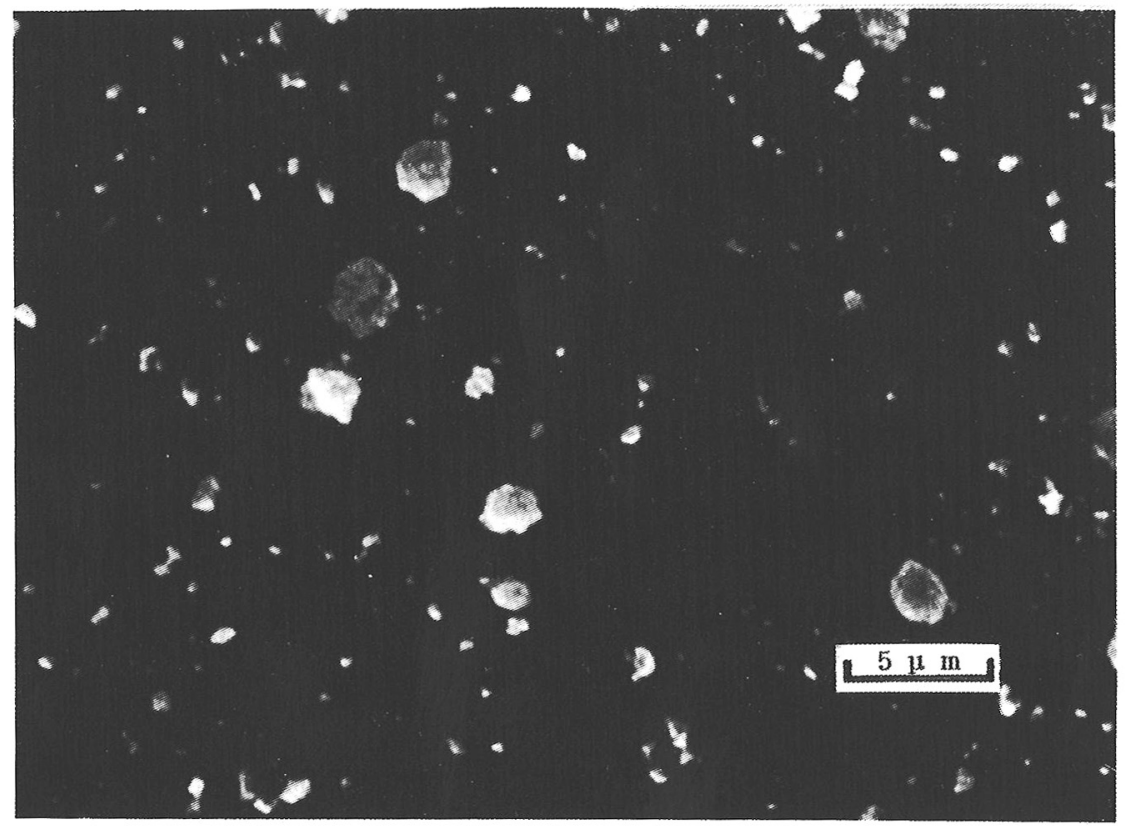

Fig. 4. Scanning electronmicrographs of chromium fume (A) and nickel fume (B) particles collected from the exposure chamber. 

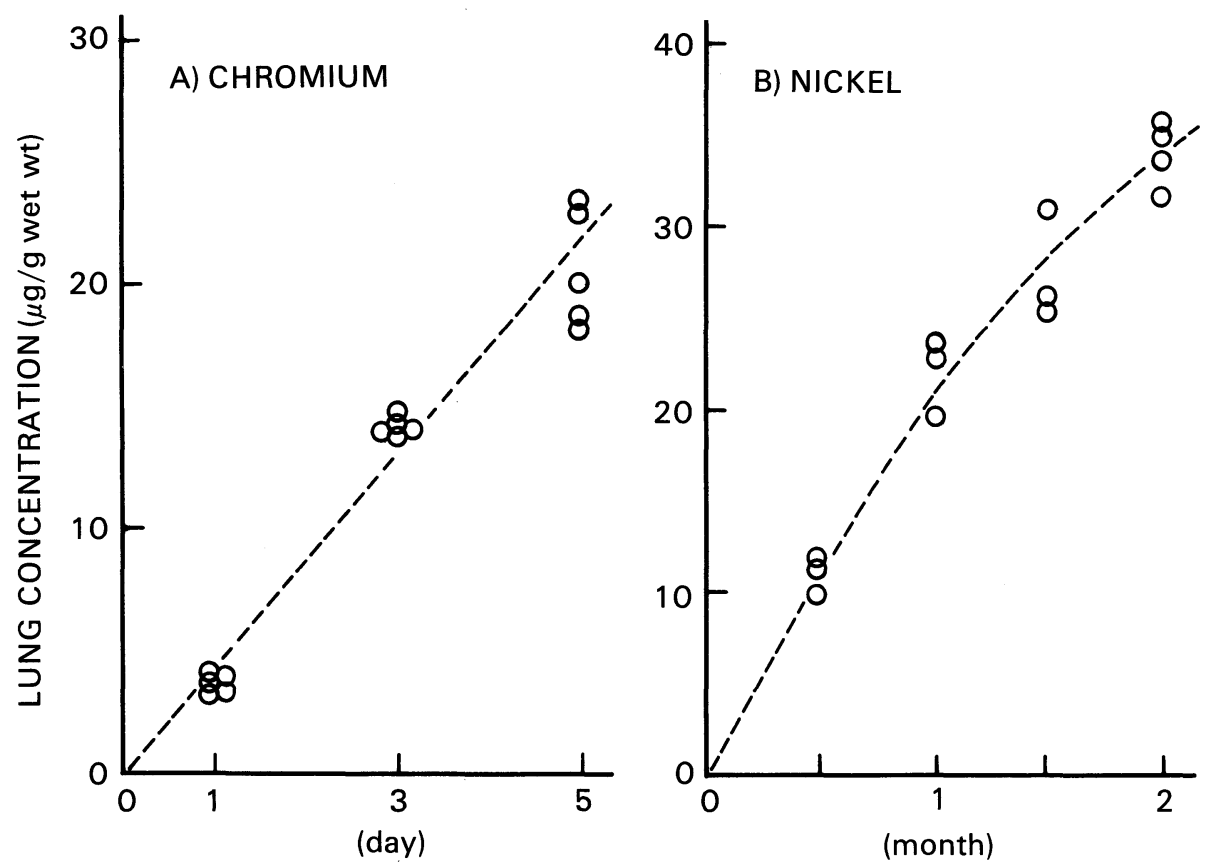

INHALATION PERIOD

Fig. 5. Chromium (A) and nickel (B) concentrations in the lungs of rats exposed to chromium and nickel fumes.

concentration of chromium fumes was $1.85 \mathrm{mg} / \mathrm{m}^{3}$, close to the target level $\left(2 \mathrm{mg} / \mathrm{m}^{3}\right)$. MMAD of the fume particles was $2.1 \mu \mathrm{m}$ and $\sigma \mathrm{g}$ was 2.00 . The species analysis of the chromium fume particles revealed that $26.4 \%$ (a mean of five measurements) of the total chromium was hexavalent chromium and the residue was trivalent. The exposure concentration of nickel fumes was 0.51 $\mathrm{mg} / \mathrm{m}^{3}$ and approximately equal to the target level of $0.5 \mathrm{mg} / \mathrm{m}^{3}$. The species analysis of two samples of the nickel fume particles showed that 1.2 and $3.2 \%$ of the total nickel were nickel(III) species, respectively and that the residues were nickel(II) species.

\section{Animal conditions and lung retention of inhaled metals}

Normal gains in body weight were observed in both experimental and control groups during the whole experimental periods of chromium and nickel fume inhalation. No abnormal behavior of the animals was observed during the experiments.

Figure 5A shows the chromium concentrations in the lungs exposed to chromium fumes up to one week. The chromium increase was approximately proportional to repeated exposure. Coefficients of variation of the concentrations 
determined after the first, third and fifth exposure were 8.3, 2.4 and $11.2 \%$, respectively. The control levels of lung chromium were less than $0.1 \mu \mathrm{g} / \mathrm{g}$ wet wt and did not show any time-dependent increase. The nickel concentrations in the lungs exposed to nickel fumes increased with the exposure period and reached 34 $\mu \mathrm{g} / \mathrm{g}$ wet wt after two-month exposure as shown in Fig. $5 \mathrm{~B}$. The coefficients of variation ranged from 5.2 to $11.7 \%$ during the experimental period. The control levels of lung nickel were $4.8 \pm 2.5 \mathrm{ng} / \mathrm{g}$ wet wt, showing no significant increase with the prolonged experimental period.

It seemed that the coefficients of variation of the inhaled-metal concentrations were within the normal range seen in analytical results from these kinds of animal experiments.

\section{Discussion}

In the present experiments, a plasma flame metal sprayer (PFMS) was used to generate metal fumes from chromium and nickel powders. PFMS has been shown to be useful for generation of iron fumes from iron powder. ${ }^{2)}$ The present results demonstrate that PFMS was useful also for generating chromium and nickel fumes and would be useful for generating fumes from other high melting point metals. However, PFMS-generated metal fumes were unsuitable for direct use for inhalation experiments, because of the concomitant contamination of ozone and nitrogen oxides as well as the high-temperature atmosphere including high levels of rare gases used for the plasma flame formation. Harsh noise and ultra-violet radiation from PFMS were also troublesome. GBFC was devised to exclude these disadvantages. It was possible to prepare a large amount of fume particles while easily excluding the disadvantages.

The chemical analysis revealed that two oxidation states existed in the chromium and the nickel fumes. A preliminary experiment of fume generation showed that the higher power of PFMS resulted in higher contents of hexavalent chromium. The results suggest that the conditions of fume generation are closely related to the oxidation states of the fume particles. Further research on the effects of fume-generating conditions on the oxidation states are needed.

In whole-body inhaltion experiments, chambers of a rectangular or a hexagonal cross-section type with a pyramidal top and bottom have been usually used. ${ }^{11-14)}$ In some vertical flow chambers, multi-tier cage arrangements have been used. They are unsanitary, because animals on lower tiers are contaminated with the excreta of the animals on higher tiers. To avoid these disadvantages, a single-tier cage arrangement has been widely accepted for long-term inhalation experimens. ${ }^{13,14)}$ However, inhalation chambers of this type require larger floor space compared to multi-tier type chambers. In the present experiments, horizontal flow chambers having mobile cage racks equipped with four shelves and fecal catch pans were developed. The capacity for housing animals is greater compared to that of a 
vertical flow type. Our chambers protect the animals from excreta contamination and provide easy animal care. The chamber conditions had no problems for animal growth, as shown by the normal gains in body weight during the experimental periods.

Although Hemenway and MacAskill ${ }^{15)}$ developed a small-scale horizontal flow inhalation chamber, its performance was not entirely satisfactory. However, our horizontal flow chamber showed uniform aerosol distribution as seen in Table 2. The rectification plates and fecal catch pans probably facilitated the uniform distribution of aerosols.

The present animal experiments were designed for short-term exposure to chromium fumes at a high level and for long-term exposure to nickel fumes at a low level. The steady increases with the normal ranges of variation in the lung concentrations of the inhaled metals (Fig. 5) demonstrate that the performance of the system is stable and reproducible enough to execute inhalation experiments using high melting point metal fumes at both low and high levels. No significant increase of examined metals in the lungs of the control animals show that no problems of metal fume contamination occurred in the long-term operation of the system.

\section{ACKNOWLEDGEMENTS}

This study was supported by a grant from the Japan Environmental Agency. The authors wish to thank Mrs. S. Kurimori and Mr. S. Kishida of this institute for technical assistance.

\section{REFERENCES}

1) Cass GR, McRae GJ. Emissions and air quality relationships for atmospheric trace metals. In: Nriagu JO, Davidson CI, eds. Toxic metals in the atmosphere. New York: Wiley-Interscience, 1986: 145-71.

2) Serita F. A new technique for generating heavy metal fumes with high melting point. Ind health 1983; 21: 67-77.

3) Tanaka I, Akiyama T. A new dust generator for inhalation toxicity studies. Ann Occup Hyg 1984; 28: 157-62.

4) JIS K 0104 1968, 1984 revised.

5) Sawatari K, Serita F. Determination of chromium speciation in fumes prepared by a plasma metal sprayer as a model of actual welding fumes. Ind Health 1986; 24: 51-61.

6) Sawatari K. Differential determination of nickel(II) oxide and nickel(III) oxide in airbone particulate substances. Ind Health 1988; 26: 115-23.

7) Kyono H, Homma K, Serita F, Sawatari K, Suzuki Y, Koshi K, Saegusa J, Fukuda K. Lung lesions induced by the inhalation of metal oxides generated from metals of high melting temperature. In: Masuda S, Takahashi K, eds. Aerosols: Science, Industry, Health and Environment. Oxford: Pergamon Press, 1990; Vol. II 1267-70.

8) Koshi K, Serita F, Sawatari K, Suzuki Y. Cytogenetic analysis of bone marrow cells and peripheral blood lymphocytes from rats exposed to chromium fumes by inhalation. Mutation Res $1987 ; 182: 365$. 
9) Koshi K, Serita F, Suzuki Y. Cytogenetic analysis of bone marrow cells and peripheral blood lymphocytes from rats exposed to nickel fumes by inhalation. Environ Mutagen Res Commun 1987; 9: 31. (In Japanese)

10) Koshi K. Cytogenetic findings in rats exposed to metal fumes. Microelements, Proceedings of the Workshop of the Japanese Society for Hygiene 1989. 45-53. (In Japanese)

11) Leach LG, Spiegl CJ, Wilson RH, Sylvester GE, Lauterbach KE. A multiple chamber exposure unit designed for chronic ihnalation studies. Am Ind Hyg Assoc J 1959; 20: 13-22.

12) Hinners RG, Burkart JK, Punte CL. Animal inhalation exposure chambers. Arch Environ Health 1968; 16: 194-206.

13) Phalen RF, Mannix RC, Drew RT. Inhalation exposure methodology. Environ Health Perspect 1984; $56: 23-34$.

14) Fukuda $K$, Takemoto $K$, Tsuruta $H$. Inhalation carcinogenicity of trichloroethylene in mice and rats. Ind Health 1983; 21 : 243-54.

15) Hemenway DR, MacAskill SM, Design, development and test results of a horizontal flow inhalation toxicoloty facility. Am Ind Hyg Assoc J 1982; 43:874-9. 